\title{
Physiotherapy treatment and rehabilitation following anterior cruciate ligament injury in New Zealand: Are we doing enough?
}

Wayne Fausett MHIthPrac, BHSC (Physiotherapy), PGDipPE, BPhEd Clinical Advisor, Accident Compensation Corporation, Tauranga, New Zealand

Fraser Wilkins MHIthPrac, PGDip (Rehab), PGCertHSC, BHSC (Physiotherapy) Clinical Advice Manager, Accident Compensation Corporation, Hamilton, New Zealand

Duncan Reid DHSC, MHSC, PGDipHSC (Manipulative Physiotherapy), DipMT, DipPhys, BSC Professor, School of Clinical Sciences, Auckland University of Technology, Auckland, New Zealand

Peter Larmer DHSc, MPH, DipPhys, Dip Acupuncture

Associate Professor, School of Clinical Sciences, Auckland University of Technology, Auckland, New Zealand

Geoff Potts MHSc, PGDipHSc (Sports Physiotherapy), PGCertHSc (Western Acupuncture), BHSc (Physiotherapy)

Clinical Director, KneeCare, Auckland, New Zealand

\section{ABSTRACT}

Physiotherapists are lead providers of rehabilitation following anterior cruciate ligament injury in New Zealand. Rehabilitation is considered an essential component following anterior cruciate ligament injuries, but there is considerable variability regarding preand post-operative management. This study used data from the Accident Compensation Corporation (ACC) for the years 2013/14 to 2015/16 to gain insight into the physiotherapy management of anterior cruciate ligament injuries in New Zealand. Data were extracted from 647 claims from people with a completed anterior cruciate ligament reconstruction and 221 claims from people with a confirmed injury who did not undergo surgery. In the 12 months following either anterior cruciate ligament injury or surgery, $81 \%$ of claimants had fewer than 15 ACC-funded physiotherapy treatments, and $13 \%$ of claimants had no ACC-funded physiotherapy treatments. Nine percent of claimants had a previous or subsequent claim for an anterior cruciate ligament injury. Compared to best practice literature, the results indicate a significant number of people in New Zealand received fewer than the recommended number of physiotherapy treatments following anterior cruciate ligament injury. Possible reasons may include the cost of private physiotherapy services, a lack of endorsement from the respective orthopaedic surgeons, decreased patient adherence/motivation and decreased patient understanding of the importance of rehabilitation.

Fausett, W., Wilkins, F., Reid, D., Larmer, P., \& Potts, G. (2019). Physiotherapy treatment and rehabilitation following anterior cruciate ligament injury in New Zealand: Are we doing enough? New Zealand Journal of Physiotherapy, 47(3), 139-149. https://doi.org/10.15619/NZJP/47.3.02

Key Words: Anterior Cruciate Ligament, Physiotherapy, Treatment, Rehabilitation

\section{INTRODUCTION}

Injury to the anterior cruciate ligament $(\mathrm{ACL})$ of the knee is a common occurrence in an active population (Gianotti, Marshall, Hume, \& Bunt, 2009; Majewski, Susanne, \& Klaus, 2006). Following $A C L$ injury, the two traditional management pathways are: 1) early $A C L$ reconstruction (ACLR) surgery followed by rehabilitation; and 2 ) conservative management consisting of rehabilitation, with the option of delayed ACLR if required (Beynnon, Johnson, Abate, Fleming, \& Nichols, 2005; Risberg, Lewek, \& Snyder-Mackler, 2004; Zadro \& Pappas, 2018). The exact incidence of $A C L$ injury is not known as not all $A C L$ injuries are diagnosed or proceed to surgery (Janssen, Orchard, Driscoll, \& Van Mechelen, 2012). ACL surgical rates are often used as surrogate estimates of injury rates (Moses, Orchard, \& Orchard, 2012; Sanders, Maradit Kremers, Bryan, Larson, et al., 2016), with rates of ACLR increasing worldwide (Abram, Price, Judge, \& Beard, 2019; Sanders, Maradit Kremers, Bryan, Larson, et al., 2016; Zbrojkiewicz, Vertullo, \& Grayson, 2018). An increasing ACLR rate is associated with increased work absenteeism, rehabilitation costs and an increased rate of degenerative knee conditions and knee joint arthroplasty (Barenius et al., 2014; Cinque, Dornan, Chahla, Moatshe, \& LaPrade, 2017; Janssen et al., 2012; Khan et al., 2018; Suter et al., 2017).

The Accident Compensation Corporation (ACC) of New Zealand provides 24-hour comprehensive no-fault accident insurance to compensate the injured person and assist them in returning to independence by covering medical costs, other entitlements and ensuring timely access to treatment (Flood, 2000). Annually, ACC spends over $\$ 25$ million on ACL surgeries and over $\$ 100$ million on physiotherapy services for all injuries (ACC, 2018a). Entitlements and the cost of physiotherapy treatment will vary depending on the injured person's work status or capacity and the contracts held by the treating physiotherapist. ACC purchases physiotherapy treatment in three ways: either via the cost of treatment regulations or the physiotherapy services contract (ACC, 2018b) or vocational rehabilitation services (VRS). The ACC contribution may not fully cover the cost of treatment and some private physiotherapy practices charge a co-payment 
of up to $\$ 50$ per treatment (Fitzjohn, 2007). Claimants who are unable to complete work duties and receive earnings-related compensation (ERC) are entitled to VRS, which support and facilitate a return to work (ACC, 2015), are fully funded and may include physiotherapist-led functional rehabilitation (ACC, 2018c).

Rehabilitation following ACL injury or ACLR should encompass a biopsychosocial approach (Scott, Perry, \& Sole, 2018), which addresses patient education, physical rehabilitation and psychological barriers (Filbay \& Grindem, 2019; Risberg, Grindem, \& Oiestad, 2016; Zadro \& Pappas, 2018). The physical component of rehabilitation involves restoration of knee range of movement, lower limb strengthening, neuromuscular and proprioceptive retraining, and activity specific exercises (Adams, Logerstedt, Hunter-Giordano, Axe, \& Snyder-Mackler, 2012; Myer, Paterno, Ford, Quatman, \& Hewett, 2006). Physical rehabilitation following ACL injury is safe and efficacious (Eitzen, Moksnes, Snyder-Mackler, \& Risberg, 2010), with the ultimate goal of rehabilitation to achieve a sustainable return to preinjury activities (Risberg et al., 2004). Physiotherapists with expertise in the function of the musculoskeletal system have the knowledge and skills to implement and progress the physical and functional components of ACL rehabilitation (van Melick et al., 2016).

A structured pre-operative physical rehabilitation programme produces better post-operative functional outcomes (Eitzen, Risberg, \& Holm, 2009; Failla et al., 2016; Logerstedt, Lynch, Axe, \& Snyder-Mackler, 2013). Supervised physiotherapy is routinely prescribed following ACL surgery (Han, Banerjee, Shen, \& Krishna, 2015), and supervised rehabilitation can be associated with better outcomes than unsupervised (Christensen, Miller, Burns, \& West, 2017). Physical rehabilitation lasting up to 12 months is recommended after ACLR to restore function and stability to the knee (Adams et al., 2012; Zadro \& Pappas, 2018), and to optimise post-surgical outcomes (Grindem, Granan, et al., 2015). Recent evidence suggests people may not be completing sufficient post-ACLR rehabilitation before returning to pre-injury activities (Ebert, Edwards, et al., 2018; Grindem, Arundale, \& Ardern, 2018). Irrespective of how an ACL injury is managed, a significant percentage of people do not return to pre-injury activity levels (Ardern, Taylor, Feller, \& Webster, 2014; Øiestad, Holm, \& Risberg, 2018; Webster \& Feller, 2018), or they suffer a subsequent $\mathrm{ACL}$ injury (Crawford, Waterman, \& Lubowitz, 2013; Lai, Ardern, Feller, \& Webster, 2017; Wright, Magnussen, Dunn, \& Spindler, 2011).

The content and quality of $A C L$ rehabilitation protocols is highly variable (Ajuied et al., 2014), which may lead to confusion among patients and physiotherapists (Makhni et al., 2016). Patient outcomes following ACL rehabilitation could also be influenced by patient individuality and variability in the implementation of specific $A C L$ rehabilitation protocols by physiotherapists (Adams et al., 2012; Greenberg, Greenberg, Albaugh, Storey, \& Ganley, 2018; Myer et al., 2006).

The aim of this study was to undertake a retrospective review of a three-year period of ACC claim data to gain insight into the management of ACL injury in New Zealand, with a particular focus on the quantity and duration of physiotherapy treatment following injury, and during the pre- and post-operative rehabilitation periods.

\section{METHODS}

Ethical approval was sought retrospectively. However, as advised by the Auckland University of Technology Ethics Committee, this study did not meet the threshold to require ethical approval as all data remained de-identified during collection and analysis. Use of ACC claim data complied with standard ACC consent and legal obligations related to ACC cover.

A descriptive methodology was undertaken for the study. The study cohort included all claims with an approved ACLR request for the years 2013/14, 2014/15 and 2015/16 (the year being 1 July to 31 June). Claims with an approved ACLR request were assumed to have a confirmed diagnosis of an ACL rupture. ACC claim numbers were used to identify claims. Claims were categorised as either surgical for those who had undergone surgery (Surgery Group) or non-surgical (Non-Surgery Group), and were stratified by gender and age at the date of injury (DOI) $(<20,20-29,30-39,40-49,50+$ years of age). Using a random number generator in Microsoft Excel, a sample of 20 claims was selected from each year according to age and gender. Where there were fewer than 20 claims for an age and gender group for that year, all claims were included in the sample. Convenience sampling was used to ensure the total sample included a similar number of males and females, and that all age ranges were equally represented. In addition, all claims where individuals had undergone ACL surgery more than 365 days after DOI were categorised as "delayed surgery" (Delayed Surgery Group), and data from this group were analysed separately.

For the Surgery Group and Non-Surgery Group, data collected via ACC's internal database and payments system included:

- mechanism of injury

- activity being performed when ACL injury occurred

- date of last physiotherapy treatment

- total earnings-related compensation (ERC) days paid under that claim

- whether there was an approved purchase order for vocational rehabilitation in the 12 months following surgery or injury

- whether the client had suffered a previous or subsequent $A C L$ injury.

Additional data collected for the Surgery Group included the date of surgery, number of pre-ACLR physiotherapy treatments and number of post-ACLR physiotherapy treatments within 12 months of surgery. Additional data collected for the NonSurgery Group included the total number of physiotherapy treatments within 12 months of injury. The 12-month period was chosen as this is the recommended duration of rehabilitation following $A C L$ injury (van Melick et al., 2016). 
The selection of claims for analysis is described in Figure 1. From the Surgery Group, two claims were excluded as the clients had not undergone $A C L R$, and one claim was excluded as the $A C L$ was found intact at the time of surgery. From the Non-Surgery Group, six claims were excluded as the $A C L$ was subsequently revealed to be intact, and seven claims were excluded as the clients had undergone ACLR within 12 months of injury. Overall, the Surgery Group, Delayed Surgery Group, and Non-Surgery Group represented $8 \%, 2.5 \%$, and 3.5\% respectively of the total population.

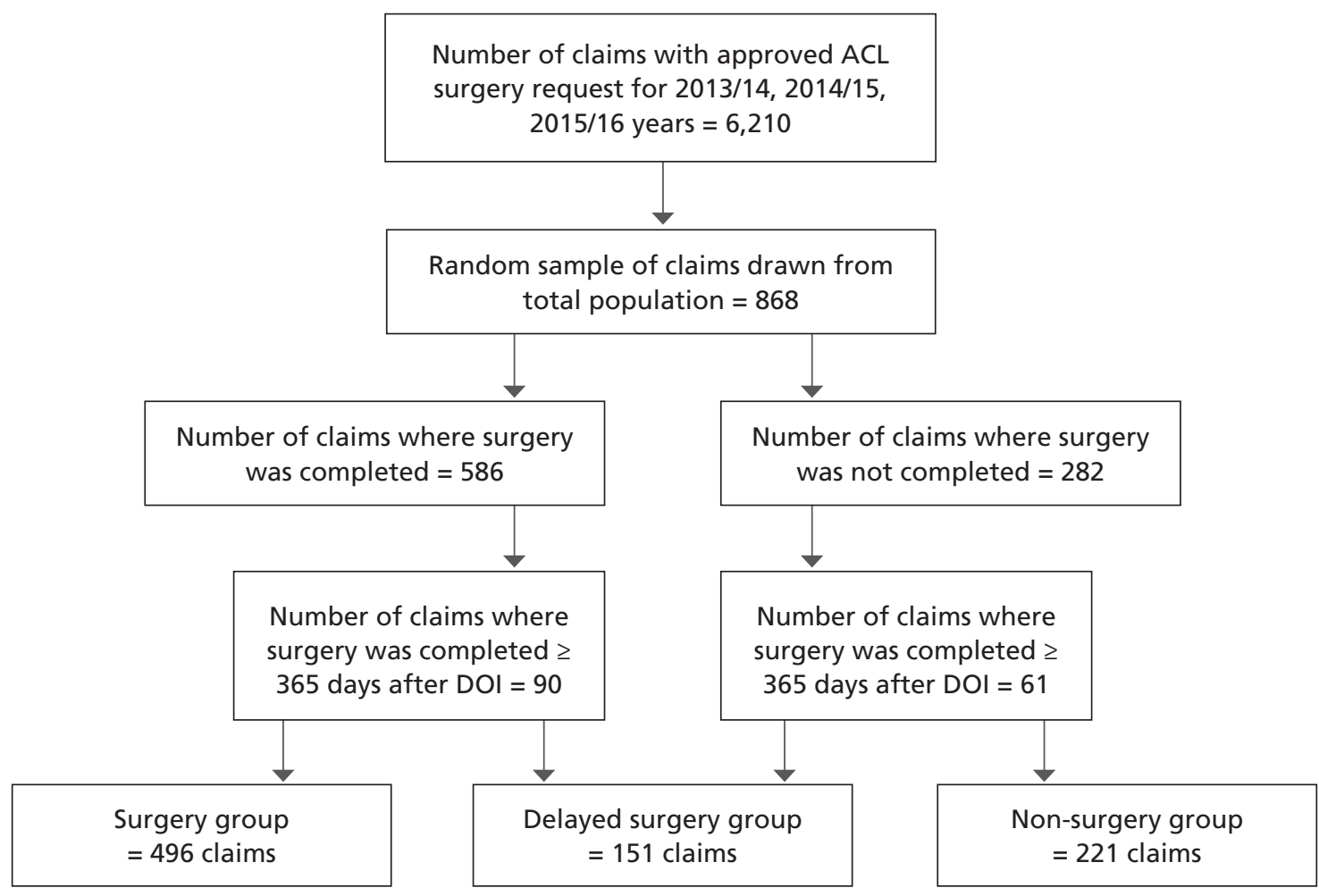

Figure 1: Flow diagram describing sample selection and how each study group was determined

Note: $\mathrm{ACL}$, anterior cruciate ligament; $\mathrm{DOI}$, date of injury

Across the three groups, average age at DOI was $33.4 \pm 13.2$ years (range 9-74 years). The percentage of male subjects was $48 \%, 62 \%$ and $58 \%$ respectively. The most common activity being performed when suffering an $A C L$ injury was sports followed by recreational activities (Figure 2). Netball was the most common sport being played when suffering an $\mathrm{ACL}$ injury, followed by rugby, soccer and touch rugby (Figure 3). Notably, 74\% (642/868) of ACL injuries involved a non-contact mechanism of injury.

Duration and quantity of physiotherapy treatment For the Surgery Group ( $n=496), 120$ claims $(24.2 \%)$ had no pre-ACLR physiotherapy treatments. Of the 376 claims $(75.8 \%)$ with pre-ACLR physiotherapy treatments, the number of treatments averaged $7 \pm 5$ (range 1-33) (Figure 4). In the 12 months following ACLR, 456 claims (91.9\%) had postACLR physiotherapy treatment, with the average number of treatments being $12 \pm 8$ (range 1-54) (Figure 5). The average time between surgery and the last physiotherapy treatment was $161 \pm 143$ days.

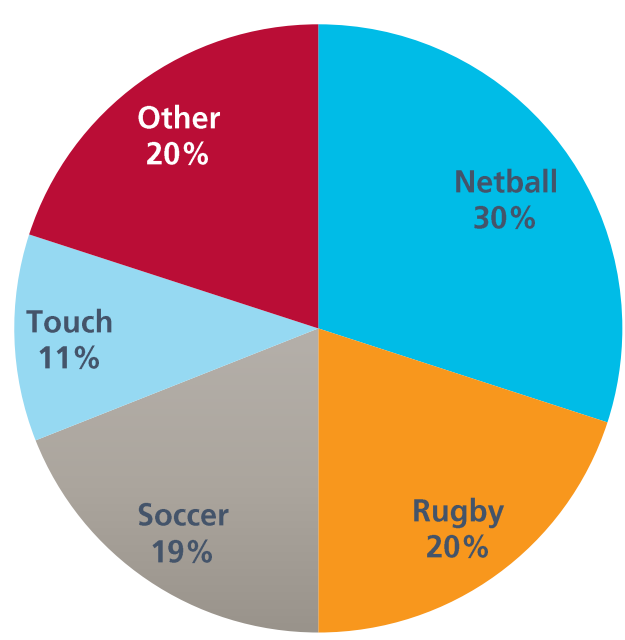

Figure 2: Activity being performed when anterior cruciate ligament injury occurred 


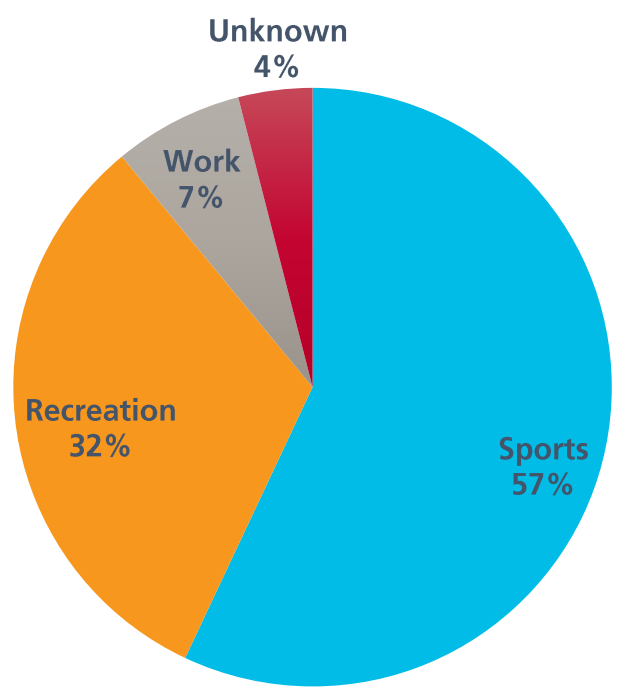

Figure 3: Sport being played when anterior cruciate ligament injury occurred

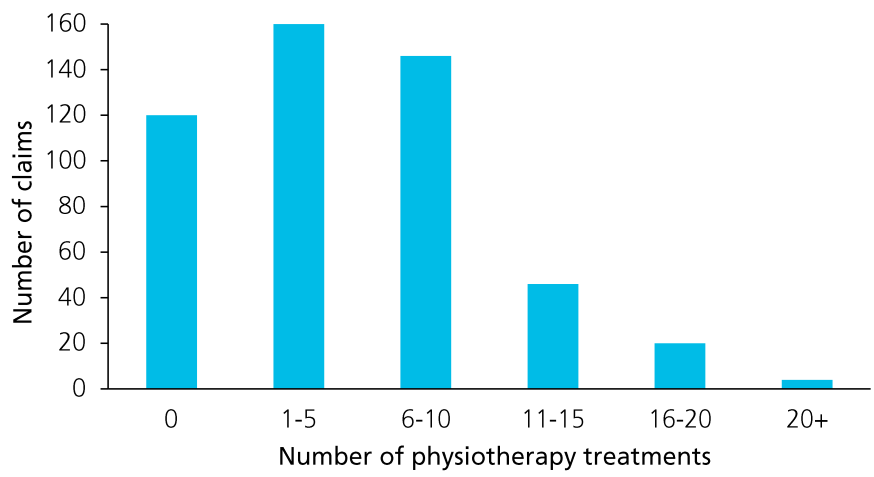

Figure 4: Number of physiotherapy treatments for the Surgery Group prior to anterior cruciate ligament surgery

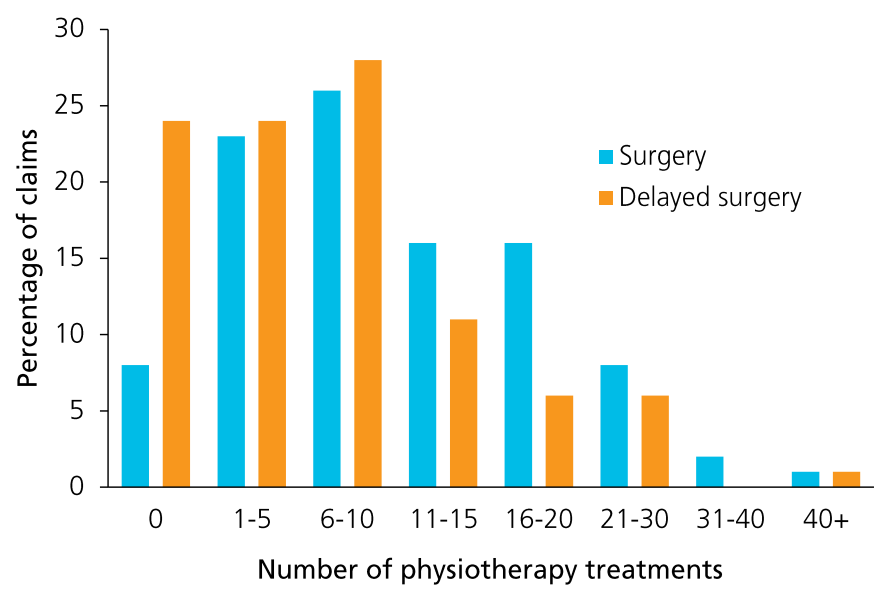

Figure 5: Number of physiotherapy treatments per claim for the Surgery Group and Delayed Surgery Group in the 12 months following anterior cruciate ligament surgery
For the Delayed Surgery Group ( $\mathrm{n}=151), 109$ claims $(72.1 \%)$ had physiotherapy treatment in the 12 months following DOI, with an average of $8 \pm 8$ (range 1-49) treatments (Figure 6). In the 12 months following ACLR, 115 claims (76.1\%) had physiotherapy treatment, with the average number of treatments being $10 \pm 9$ (range 1-59) (Figure 5). The average time between surgery and the last physiotherapy treatment was $143 \pm 95$ days.

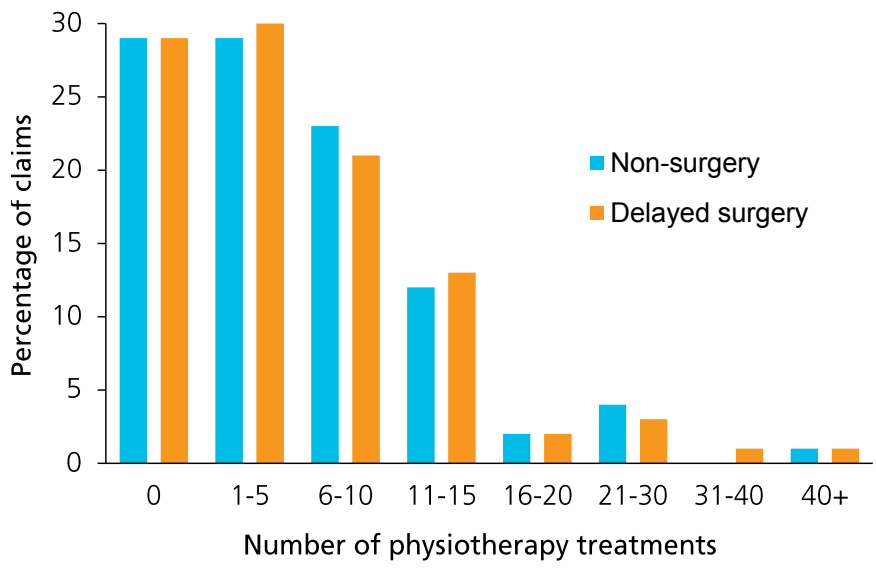

Figure 6: Number of physiotherapy treatments per claim for the Non-Surgery Group and Delayed Surgery Group in the 12 months following anterior cruciate ligament injury

For the Non-Surgery Group ( $n=221), 157$ claims (71.0\%) had physiotherapy treatment in the 12 months following DOI, with an average of $8 \pm 6$ (range 1-42) treatments (Figure 6). The average time between $\mathrm{DOI}$ and the last physiotherapy treatment was $90 \pm 84$ days.

\section{Earnings related compensation and vocational rehabilitation}

For the Surgery Group, 80 claims (16.1\%) had ERC paid in the two weeks prior to ACLR. Following surgery, 247 claims (49.8\%) had ERC paid for an average of $102 \pm 93$ days (range 3-809). In the 12 months after ACLR, 129 claims (26.0\%) had approved VRS, with an average duration of $149 \pm 100$ days (range 3-809) of ERC paid. For claims with approved VRS, the average number of physiotherapy treatments in the 12 months following ACLR was $11 \pm 8$ (range 1-54). Of the 40 claims (8.0\%) with no postACLR physiotherapy treatments, nine had approved VRS, and the average number of ERC days paid on those claims was 181 \pm 63 .

For the Delayed Surgery Group, nine claims (6\%) had ERC paid in the two weeks prior to ACLR. Following surgery, 63 claims $(41.7 \%)$ received ERC for an average of $93 \pm 104$ days (range 11-611). In the 12 months after ACLR, 35 claims (23.1\%) had approved VRS, with an average duration of $118 \pm 122$ days (range 27-611) ERC paid. For claims with approved VRS, the average number of physiotherapy treatments in the 12 months following ACLR was $11 \pm 7$ (range 2-29). Of the 36 claims $(23.8 \%)$ with no post-ACLR physiotherapy treatments, three had approved VRS, with an average number of ERC days paid of 84 . 
For the Non-Surgery Group, in the 12 months following injury, nine claims (4.0\%) had approved VRS, with an average of 147 \pm 98 days (range 44-317) of ERC paid. For claims with approved VRS, the average number of physiotherapy treatments in the 12 months following DOI was $9 \pm 7$ (range 2-23). Of the 64 claims $(28.9 \%)$ with no physiotherapy treatments in the 12 months following DOI, two had approved VRS, with an average of 173 days paid ERC.

\section{Time to surgery}

For the Surgery Group, the average number of days between DOI and ACLR was $121 \pm 74$ (range 22-361), with 228 people (45.9\%) undergoing ACLR within 90 days of injury and 397 people (80.0\%) undergoing ACLR within 180 days of injury (Figure 7). For the Delayed Surgery Group, the time between DOI and ACLR was on average $908 \pm 565$ days (range 3692939).

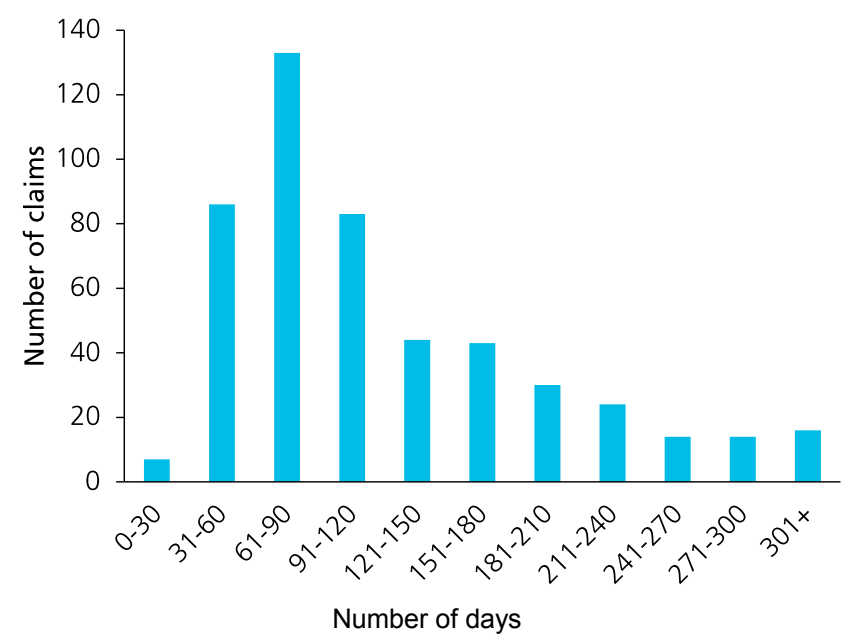

Figure 7: Number of days between anterior cruciate ligament injury and surgery for the Surgery Group

Subsequent ACL injury

For all groups ( $n=868), 95$ people $(10.9 \%)$ had suffered multiple ACL injuries. Across the Surgery Group and Delayed Surgery Group $(n=647), 50$ people $(7.7 \%)$ suffered a subsequent $A C L$ injury following $A C L R$, i.e. 33 (5.1\%) $A C L$ graft ruptures and 17 (2.6\%) contralateral $A C L$ injuries. The average duration between ACLR and subsequent ACL injury was 617 \pm 371 days and 1,210 \pm 855 days for the Surgery Group and Delayed Surgery Group, respectively. For both groups, 28 people (4.3\%) had suffered a previous contralateral ACL injury and three had sustained a previous ipsilateral $A C L$ injury.

For the Non-Surgery Group, one individual suffered a contralateral $A C L$ injury 392 days after the initial $A C L$ injury; 11 had suffered a previous contralateral $A C L$ injury, eight of whom had undergone $A C L R$, with two sustaining subsequent $A C L$ graft ruptures.

\section{DISCUSSION}

The aim of this study was to present a retrospective descriptive analysis of ACC claim data to gain insights into the duration and quantity of physiotherapy treatment following $\mathrm{ACL}$ injury in New Zealand. Our findings show that sporting and recreational activities accounted for the majority of $A C L$ injuries, with popular change-of-direction activities in New Zealand (e.g. netball, rugby, soccer and touch rugby) responsible for the greatest number of sporting $A C L$ injuries, which is similar to previous findings (Gianotti et al., 2009; New Zealand ACL Registry, 2018). Nearly three-quarters of all $A C L$ injuries in the current study involved a non-contact mechanism of injury, which is consistent with previous reports of $72 \%$ prevalence (Boden, Dean, Feagin, \& Garrett, 2000).

\section{Duration and quantity of physiotherapy treatment} Our results suggest New Zealanders are not receiving physiotherapy treatment for an appropriate duration following $A C L$ injury or surgery. Post-ACLR rehabilitation lasting up to 12 months is associated with improved knee flexor/extensor strength (Ageberg, Thomeé, Neeter, Silbernagel, \& Roos, 2008; Heijne \& Werner, 2007; Risberg \& Holm, 2009), greater performance during functional testing (Ebert, Edwards, et al., 2018), a greater rate of returning to pre-injury activities (Ardern et al., 2014; Della Villa et al., 2012; Edwards et al., 2018; Han et al., 2015; Rosso et al., 2018) and decreased re-injury risk (Grindem, Snyder-Mackler, Moksnes, Engebretsen, \& Risberg, 2016). Traditional progressions through ACL rehabilitation have been time based, which may result in sub-optimal outcomes, as time after ACLR is not necessarily related to functional performance (Myer et al., 2012). Although post-surgical rehabilitation is recommended for nine to 12 months (van Melick et al., 2016), criterion-based measures of functional performance, incorporated within a biopsychosocial framework, are also recommended to determine rehabilitation progress (Dingenen \& Gokeler, 2017; Larsen, Farup, Lind, \& Dalgas, 2015; Myer et al., 2006).

Our results have highlighted a potential under-utilisation of physiotherapy treatment following ACL injury and surgery, and prior to ACLR in New Zealand. Physiotherapists consider pre-operative rehabilitation to have an important influence on post-operative outcomes (Ebert, Webster, Edwards, Joss, D'Alessandro, et al., 2018). A structured physiotherapy-led preACLR rehabilitation programme of up to 27 sessions has been shown to be effective and safe, and to improve outcomes two years after ACLR (Alshewaier, Yeowell, \& Fatoye, 2017; Eitzen et al., 2010; Eitzen et al., 2009; Failla et al., 2016; Logerstedt et al., 2013). Our research found that $24 \%$ of people did not receive physiotherapy treatment prior to $A C L R$, which suggests the post-operative outcomes for almost a quarter of people in our sample may have been sub-optimal.

While many factors potentially influence outcomes after $A C L$ injury and surgery, rehabilitation remains an important variable (Ebert, Webster, Edwards, Joss, D'Allesandro, et al., 2018) and is almost universally recommended (Adams et al., 2012; Ebert, Webster, Edwards, Joss, D'Alessandro, et al., 2018; Lobb, Tumilty, \& Claydon, 2012; van Melick et al., 2016). Over $80 \%$ of Australian physiotherapists believe six to 12 treatments are required in the first six weeks after $A C L$ surgery (Ebert, Webster, Edwards, Joss, D'Alessandro, et al., 2018), with a physiotherapist review recommended every two weeks (Filbay \& Grindem, 2019). Therefore, rehabilitation lasting from nine to 
12 months would equate to between 21 and 35 physiotherapy visits within 12 months following ACL surgery. It appears people in the current study received considerably less physiotherapy treatment than evidence-based guidelines suggest; the reasons for this require further evaluation.

There are multiple barriers to people engaging in a healthcare service, which includes physiotherapy following ACL injury/ surgery (Carrillo et al., 2011). Patient-specific barriers include health literacy/understanding of the condition, cultural beliefs and socio-economic status; provider-specific barriers include clinician skills/knowledge and patient interactions; healthcare system barriers include cost, accessibility/waiting times, location of services and the involvement of multiple providers (Bath et al., 2016; Douthit, Kiv, Dwolatzky, \& Biswas, 2015; Scheppers, Van Dongen, Dekker, Geertzen, \& Dekker, 2006). In New Zealand, barriers to engaging with primary healthcare services include location, cost, suitability and awareness of services (Ministry of Health, 2001). Strategies to overcome these barriers include encouraging early, appropriate intervention within a patient's locale, ensuring cost- effective services within an accountable healthcare system and empowering people by improving health literacy through quality education (Ministry of Health, 2016).

The cost of private physiotherapy services may influence physiotherapy utilisation (Ebert, Webster, Edwards, Joss, D'Alessandro, et al., 2018). ACL rehabilitation in New Zealand is commonly supplied by private physiotherapy providers, who may charge a co-payment of up to $\$ 50$ per treatment. Although physiotherapy is available via the public health system at no cost, the vast majority of people seek physiotherapy from private providers (ACC, 2018a), who make up almost $70 \%$ of New Zealand's physiotherapy workforce (Physiotherapy New Zealand, 2018). Although there are a small number of private physiotherapists in New Zealand who do not charge a copayment, unless the person is receiving VRS from ACC, it is likely they will have to contribute to the cost of physiotherapy treatment or rehabilitation services. As such, socio-economic status could be a barrier to utilisation of physiotherapy services.

A lack of endorsement of rehabilitation by orthopaedic surgeons may have influenced physiotherapy treatment numbers in this study. Almost $40 \%$ of orthopaedic surgeons in Australia do not consider pre-ACLR rehabilitation necessary, and a small percentage even consider post-ACLR rehabilitation unnecessary (Ebert, Webster, Edwards, Joss, D'Allesandro, et al., 2018). While the surgeon is responsible for the surgery, the physiotherapist should lead the decision-making in rehabilitation (van Melick et al., 2016). Good communication between the surgeon and physiotherapist is essential following ACL injury (Grindem et al., 2018) to overcome any potential disconnect between providers (von Aesch, Perry, \& Sole, 2016).

$A C L$ rehabilitation is described by some patients as time consuming and boring, and perceived as being unable to provide sufficient results within a reasonable timeframe (Thorstensson, Lohmander, Frobell, Roos, \& Gooberman-Hill, 2009); this is likely to contribute to decreased compliance with rehabilitation exercises following ACLR (Risberg et al., 2016). Poor adherence to treatment recommendations may influence physiotherapy utilisation and have a significant impact on clinical outcomes (Pizzari, McBurney, Taylor, \& Feller, 2002; Vermeire, Hearnshaw, Van Royen, \& Denekens, 2001). Early physiotherapeutic intervention after ACL injury, including education about the importance of rehabilitation, could positively influence the patient experience and may increase adherence to rehabilitation (Grindem, Risberg, \& Eitzen, 2015; Risberg et al., 2016; Scott et al., 2018). Increased adherence to rehabilitation is positively associated with functional ability following ACLR (Brewer et al., 2000; Pizzari, Taylor, McBurney, \& Feller, 2005; Rosso et al., 2018).

Patients may not be adequately informed about the rehabilitation requirements after $A C L$ surgery (Cailliez et al., 2012). Limited understanding of the importance of rehabilitation can negatively influence patient motivation (Grindem, Risberg, et al., 2015) and patients may have high expectations regarding functional outcomes after primary ACLR (Webster \& Feller, 2019). Although patient expectations align closely with the surgeons (Khair, Ghomrawi, Wilson, \& Marx, 2018), the reality is these expectations are frequently not met (Ardern et al., 2014). A lack of patient education regarding the rehabilitation requirements may contribute to unrealistic patient expectations concerning the outcomes of ACLR (Feucht et al., 2016; Heijne, Axelsson, Werner, \& Biguet, 2008). Therefore, an effective clinician-patient relationship incorporating education on the requirements and importance of rehabilitation may improve patient motivation and adherence, increasing physiotherapy utilisation and the likelihood of an optimal outcome (Scott et al., 2018).

Although the number of ACC-funded physiotherapy treatments under a claim may provide an indication of the amount of rehabilitation the individual received, it cannot be assumed this accurately reflects their total rehabilitation. Other potential sources of rehabilitation include orthopaedic surgeons or other allied health professionals (Ebert, Webster, Edwards, Joss, D'Alessandro, et al., 2018), ACC-funded rehabilitation under VRS, non-clinically led rehabilitation (e.g. fitness trainer or gym instructor), privately funded physiotherapy or self-directed rehabilitation. Our results showed that for claims with approved VRS in the 12 months following ACL injury or surgery, the average number of physiotherapy treatments was very similar to claims without approved VRS, which indicates VRS had a negligible impact on the number of physiotherapy treatments per claim.

There is no clear evidence that supervised rehabilitation after ACLR will result in superior outcomes compared to minimally supervised rehabilitation (Anderson, Browning, Urband, Kluczynski, \& Bisson, 2016; Lobb et al., 2012), which may have contributed to low physiotherapy treatment numbers in the current study. Selected groups of patients, including young, athletic people, may achieve acceptable outcomes after ACLR with a minimally supervised rehabilitation programme involving fewer than 10 physiotherapy treatments over three to 12 months (Feller, Webster, Taylor, Payne, \& Pizzari, 2004; Grant \& Mohtadi, 2010; Hohmann, Tetsworth, \& Bryant, 2011).

Our results showed that over $70 \%$ of New Zealanders engaged in physiotherapy treatment after ACL injury, and over 90\% engaged in physiotherapy after ACLR. Ebert, Edwards et al. 
(2018) reported that $91 \%$ of people engaged in supervised rehabilitation/physiotherapy after ACLR, but $45 \%$ of people reported that rehabilitation following surgery lasted three months or less. Therefore, while the majority of people initially receive physiotherapy treatment following $A C L$ injury or surgery, our results suggest people do not remain engaged in rehabilitation for an appropriate duration.

Although our results suggest possible underutilisation of physiotherapy-led services in the 12 months following ACL injury, an absence of outcome data means the relationship between utility and outcome is currently unknown. The New Zealand ACL Registry records outcome data for people undergoing ACLR (New Zealand ACL Registry, 2018), but as details regarding the type, amount or duration of rehabilitation received prior to or following surgery are unknown, it is not possible to correlate these outcomes with rehabilitation parameters. Although outcomes following ACLR may appear to be influenced by post-operative rehabilitation (Ebert, Edwards, et al., 2018; Edwards et al., 2018), these data were collected retrospectively, with participants subjectively grading the amount, type and duration of rehabilitation they received. As details of the post-ACLR rehabilitation were not quantified prospectively, it is possible they do not accurately reflect the rehabilitation received.

\section{Time to surgery}

Almost half of the Surgery Group proceeded to ACLR within 90 days of injury, and $80 \%$ within 180 days of injury. There is no accepted definition for early or delayed ACLR (Beynnon et al., 2005), with "early" defined as between two days and seven months of DOI, and "delayed" as between three weeks and 24 years (Anderson et al., 2016). There are equivocal differences in outcomes between patients undergoing early verses delayed ACLR (Anderson et al., 2016; Eriksson, von Essen, Jönhagen, \& Barenius, 2018; Lee, Lee, Lee, \& Hui, 2018; Smith, Postle, Penny, McNamara, \& Mann, 2014; Wittenberg, Oxfort, \& Plafki, 1998), although early surgical intervention may reduce the risk of subsequent meniscal or chondral injury, both of which are associated with worse outcomes following ACLR (Cinque et al., 2018; Cox et al., 2014).

Early ACLR is common practice both domestically (New Zealand ACL Registry, 2018) and internationally (Delay, Smolinski, Wind, \& Bowman, 2001; Sanders, Maradit Kremers, Bryan, Kremers, et al., 2016). However, it can take at least six months following $A C L$ injury for the true functional disability to be defined (Noyes, Matthews, Mooar, \& Grood, 1983). A significant number of patients who may initially appear unable to cope with an $A C L$ injury are able to cope following six months of rehabilitation (Moksnes, Snyder-Mackler, \& Risberg, 2008). The time interval from $A C L$ injury to $A C L R$ may be less important as the condition of the knee at the time of surgery (Lattermann et al., 2018). Better pre-operative knee function is associated with fewer post-surgical complications and greater post-operative knee function (Beynnon et al., 2005; Filbay et al., 2017; Risberg et al., 2016). Therefore, treatment following ACL injury should involve physical rehabilitation to optimise functional ability before any decisions regarding surgical intervention are made (Eitzen et al., 2010; Thoma et al., 2019).

\section{Subsequent ACL injury}

Across all three groups, $11 \%$ of people had suffered multiple $\mathrm{ACL}$ injuries, which is slightly less than the overall rate for all ages (Wiggins et al., 2016). Younger people have a significantly higher rate of subsequent $A C L$ injury after ACLR (Webster \& Feller, 2016). Five percent of all people had suffered a previous $A C L$ injury, and $2 \%$ went on to suffer a subsequent contralateral $A C L$ injury. Following $A C L R$, graft rupture occurred in $5 \%$ of people, which is consistent with previously reported graft rupture rates (Crawford et al., 2013; Lai et al., 2017; van Yperen, Reijman, van Es, Bierma-Zeinstra, \& Meuffels, 2018; Wright et al., 2011).

\section{Limitations}

No outcomes measures were collected for any clients - as this was not the purpose of the study - which limits the conclusions regarding the adequacy of the physiotherapy treatment received. No attempt was made to make comparisons between the groups or to make associations between variables, as without outcome data, these analyses would not offer any additional insights.

\section{CONCLUSION}

$A C L$ injuries are a common injury in New Zealand, with ACC the primary funder of treatment for the condition. Rehabilitation following ACL injury can influence short- and long-term outcomes. Our results indicate the number of ACC-funded physiotherapy sessions and duration over time following $\mathrm{ACL}$ injury is highly variable. Possible reasons for this variability include financial barriers, a lack of patient understanding, a lack of endorsement of rehabilitation by the surgeon and the structure of the New Zealand healthcare system. No clinical or functional outcome data were collected in the current study, which limits the conclusions that could be drawn. However, when compared with previous research, our results indicate New Zealanders may not be accessing sufficient physiotherapy treatment following $A C L$ injury. Future research should utilise validated measures to clarify outcomes from ACL injury in New Zealand. The use of such measures will allow for investigation into associations between patient outcomes and multiple variables along the $A C L$ injury management pathway.

\section{KEY POINTS}

1. The number of physiotherapy treatments after $A C L$ injury in New Zealand is highly variable and does not appear to meet best practice guidelines.

2. The effectiveness of physiotherapy treatment for $A C L$ injury in New Zealand is unclear as patient outcomes from ACL injury in New Zealand have not been quantified.

3. Clearly defined patient reported outcome data will allow the effectiveness of physiotherapy and rehabilitation interventions to be determined.

\section{DISCLOSURES}

No funding was obtained for this study. Although ACC provided the data for analysis, ACC did not commission this research, and was not involved in the planning and conducting of this research. ACC was made aware of the study prior to its commencement and was fully supportive of the research. 
Wayne Fausett and Fraser Wilkins are employees of ACC, but this research was not undertaken in their capacity as ACC employees. Wayne Fausett is a doctoral student at the Auckland University of Technology, and this research was completed as part of his coursework. All other authors report no conflicts of interest.

\section{PERMISSIONS}

Ethical approval was sought retrospectively. However, as advised by the Auckland University of Technology Ethics Committee, this study did not meet the threshold to require ethical approval as all data remained de-identified during collection and analysis.

\section{ADDRESS FOR CORRESPONDENCE}

Wayne Fausett, Accident Compensation Corporation, PO Box 748, Tauranga 3140, New Zealand. Telephone: +64 05790326. Email: wayne.fausett@acc.co.nz.

\section{REFERENCES}

Abram, S. G. F., Price, A. J., Judge, A., \& Beard, D. J. (2019). Anterior cruciate ligament $(A C L)$ reconstruction and meniscal repair rates have both increased in the past 20 years in England: hospital statistics from 1997 to 2017. British Journal of Sports Medicine. Jan 19 https://doi.org/10.1136/ bjsports-2018-100195 [Epub ahead of print]

ACC. (2015). Statement of intent 2015-2019. Accident Compensation Corporation. Retreived from https://www.acc.co.nz/assets/corporatedocuments/7fe5022e24/acc7146-statement-of-intent-2015-2019.pdf

ACC. (2018a). ACL statistics [Excel file]. Analytics and Reporting. Accident Compensation Corporation

ACC. (2018b). Physiotherapy services: Operational guidelines. Retrieved from https://www.acc.co.nz/home/search?Search=physiotherapy+contract\&sub mit. $x=6 \&$ submit. $y=17$

ACC. (2018c). Vocational rehabilitation services: Operational guidelines. Retrieved from https://www.acc.co.nz/assets/contracts/221eb51f8a/vrsschedule.pdf

Adams, D., Logerstedt, D., Hunter-Giordano, A., Axe, M. J., \& SnyderMackler, L. (2012). Current concepts for anterior cruciate ligament reconstruction: A criterion-based rehabilitation progression. Journal of Orthopaedic and Sports Physical Thearpy, 42(7), 601-614. https://doi. org/10.2519/jospt.2012.3871

Ageberg, E., Thomeé, R., Neeter, C., Silbernagel, K. G., \& Roos, E. M. (2008). Muscle strength and functional performance in patients with anterior cruciate ligament injury treated with training and surgical reconstruction or training only: a two to five-year followup. Arthritis Care \& Research, 59(12), 1773-1779. https://doi.org/10.1002/art.24066

Ajuied, A., Smith, C., Wong, F., Hoskinson, S., Back, D., \& Davies, A. (2014). A survey of rehabilitation regimens following isolated $A C L$ reconstruction. JMED Research, 118077. https://doi.org/10.5171/2014.118077

Alshewaier, S., Yeowell, G., \& Fatoye, F. (2017). The effectiveness of pre-operative exercise physiotherapy rehabilitation on the outcomes of treatment following anterior cruciate ligament injury: A systematic review. Clinical Rehabilitation, 31(1), 34-44. https://doi. org/10.1177/0269215516628617

Anderson, M., Browning, W. M., Urband, C. E., Kluczynski, M. A., \& Bisson, L. J. (2016). A systematic summary of systematic reviews on the topic of the anterior cruciate ligament. Orthopaedic Journal of Sports Medicine, 4(3), 2325967116634074. https://doi.org/10.1177/2325967116634074

Ardern, C. L., Taylor, N. F., Feller, J. A., \& Webster, K. E. (2014). Fifty-five per cent return to competitive sport following anterior cruciate ligament reconstruction surgery: An updated systematic review and meta-analysis including aspects of physical functioning and contextual factors. British Journal of Sports Medicine, 48(21), 1543-1552. https://doi.org/10.1136/ bjsports-2013-093398
Barenius, B., Ponzer, S., Shalabi, A., Bujak, R., Norlén, L., \& Eriksson, K. (2014). Increased risk of osteoarthritis after anterior cruciate ligament reconstruction: A 14-year follow-up study of a randomized controlled trial. American Journal of Sports Medicine, 42(5), 1049-1057. https://doi. org/10.1177/0363546514526139

Bath, B., Jakubowski, M., Mazzei, D., McRae, J., McVittie, N., Stewart, S., \& Grona, S. L. (2016). Factors associated with reduced perceived access to physiotherapy services among people with low back disorders. Physiotherapy Canada, 68(3), 260-266. https://doi.org/10.3138/ptc.201550

Beynnon, B. D., Johnson, R. J., Abate, J. A., Fleming, B. C., \& Nichols, C. E. (2005). Treatment of anterior cruciate ligament injuries, part I. American Journal of Sports Medicine, 33(10), 1579-1602. https://doi. org/10.1177/0363546505279913

Boden, B. P., Dean, G. S., Feagin, J. A., \& Garrett, W. E. (2000). Mechanisms of anterior cruciate ligament injury. Orthopedics, 23(6), 573-578.

Brewer, B. W., Van Raalte, J. L., Cornelius, A. E., Petitpas, A. J., Sklar, J. H., Pohlman, M. H., ... Ditmar, T. D. (2000). Psychological factors, rehabilitation adherence, and rehabilitation outcome after anterior cruciate ligament reconstruction. Rehabilitation Psychology, 45(1), 20-37. https:// doi.org/10.1037/0090-5550.45.1.20

Cailliez, J., Reina, N., Molinier, F., Chaminade, B., Chiron, P., \& Laffosse, J-M. (2012). Patient information ahead of anterior cruciate ligament reconstruction: Experience in a university hospital center. Orthopaedics \& Traumatology, Surgery \& Research, 98(5), 491-498. https://doi. org/10.1016/j.otsr.2012.03.007

Carrillo, J. E., Carrillo, V. A., Perez, H. R., Salas-Lopez, D., Natale-Pereira, A., \& Byron, A. T. (2011). Defining and targeting health care access barriers. Journal of Health Care for the Poor and Underserved, 22(2), 562-575. https://doi.org/10.1353/hpu.2011.0037

Christensen, J. C., Miller, C. J., Burns, R. D., \& West, H. S. (2017). Effect of physical therapy visits on clinical outcomes following anterior cruciate ligament reconstruction with and without concurrent meniscal repair. Journal of Sport Rehabilitation, 28(1), 24-32. https://doi.org/10.1123/ jsr.2017-0088

Cinque, M. E., Chahla, J., Mitchell, J. J., Moatshe, G., Pogorzelski, J., Murphy, C. P., ... LaPrade, R. F. (2018). Influence of meniscal and chondral lesions on patient-reported outcomes after primary anterior cruciate ligament reconstruction at 2-year follow-up. Orthopaedic Journal of Sports Medicine, 6(2), 2325967117754189. https://doi. org/10.1177/2325967117754189

Cinque, M. E., Dornan, G. J., Chahla, J., Moatshe, G., \& LaPrade, R. F. (2017). High rates of osteoarthritis develop after anterior cruciate ligament surgery: An analysis of 4108 patients. American Journal of Sports Medicine, 46(8), 2011-2019. https://journals.sagepub.com/doi/ abs/10.1177/0363546517730072

Cox, C. L., Huston, L. J., Dunn, W. R., Reinke, E. K., Nwosu, S. K., Parker, R. D., ... Spindler, K. P. (2014). Are articular cartilage lesions and meniscus tears predictive of IKDC, KOOS, and Marx activity level outcomes after anterior cruciate ligament reconstruction? A 6-year multicenter cohort study. American Journal of Sports Medicine, 42(5), 1058-1067. https://doi. org/10.1177/0363546514525910

Crawford, S. N., Waterman, M. B. R., \& Lubowitz, J. H. (2013). Long-term failure of anterior cruciate ligament reconstruction. Arthroscopy, 29(9), 1566-1571. https://doi.org/10.1016/j.arthro.2013.04.014

Delay, B. S., Smolinski, R. J., Wind, W. M., \& Bowman, D. S. (2001). Current practices and opinions in $A C L$ reconstruction and rehabilitation: Results of a survey of the American Orthopaedic Society for Sports Medicine. American Journal of Knee Surgery, 14(2), 85-91.

Della Villa, S., Boldrini, L., Ricci, M., Danelon, F., Snyder-Mackler, L., Nanni, G., \& Roi, G. S. (2012). Clinical outcomes and return-to-sports participation of 50 soccer players after anterior cruciate ligament reconstruction through a sport-specific rehabilitation protocol. Sports Health, 4(1), 17-24. https://doi.org/10.1177/1941738111417564 
Dingenen, B., \& Gokeler, A. (2017). Optimization of the return-to-sport paradigm after anterior cruciate ligament reconstruction: A critical step back to move forward. Sports Medicine, 47(8), 1487-1500. https://doi. org/10.1007/s40279-017-0674-6

Douthit, N., Kiv, S., Dwolatzky, T., \& Biswas, S. (2015). Exposing some important barriers to health care access in the rural USA. Public Health, 129(6), 611-620. https://doi.org/10.1016/j.puhe.2015.04.001

Ebert, J., Edwards, P., Yi, L., Joss, B., Ackland, T., Carey-Smith, R., . . Hewitt, B. (2018). Strength and functional symmetry is associated with postoperative rehabilitation in patients following anterior cruciate ligament reconstruction. Knee Surgery, Sports Traumatology, Arthroscopy, 26(8), 2353-2361. https://doi.org/10.1007/s00167-017-4712-6

Ebert, J., Webster, K., Edwards, P., Joss, B., D’Alessandro, P., Janes, G. \& Annear, P. (2018). Current perspectives of Australian therapists on rehabilitation and return to sport after anterior cruciate ligament reconstruction: A survey. Physical Therapy in Sport, 35, 139-145. https:// doi.org/10.1016/j.ptsp.2018.12.004

Ebert, J., Webster, K., Edwards, P., Joss, B., D’Allesandro, P., Janes, G., \& Annear, P. (2018). Current perspectives of Australian orthopaedic surgeons on rehabilitation and return to sport after anterior cruciate ligament reconstruction. Journal of Science and Medicine in Sport, 21 (Supp/ 1), S45. https://doi.org/10.1016/j.jsams.2018.09.103

Edwards, P., Ebert, J., Joss, B., Ackland, T., Annear, P., Buelow, J., \& Hewitt, B. (2018). Patient characteristics and predictors of return to sport at 12 months after anterior cruciate ligament reconstruction: The importance of patient age and postoperative rehabilitation. Orthopaedic Journal of Sports Medicine, 6(9), 2325967118797575. https://doi. org/10.1177/2325967118797575

Eitzen, I., Moksnes, H., Snyder-Mackler, L., \& Risberg, M. A. (2010). A progressive 5-week exercise therapy program leads to significant improvement in knee function early after anterior cruciate ligament injury. Journal of Orthopaedic and Sports Physical Therapy, 40(11), 705-721. https://doi.org/10.2519/jospt.2010.3345

Eitzen, I., Risberg, M. A., \& Holm, I. (2009). Preoperative quadriceps strength is a significant predictor of knee function two years after anterior cruciate ligament reconstruction. British Journal of Sports Medicine, 43(5), 371476. https://doi.org/10.1136/bjsm.2008.057059

Eriksson, K., von Essen, C., Jönhagen, S., \& Barenius, B. (2018). No risk of arthrofibrosis after acute anterior cruciate ligament reconstruction. Knee Surgery, Sports Traumatology, Arthroscopy, 26(10), 2875-2882. https:// doi.org/10.1007/s00167-017-4814-1

Failla, M. J., Logerstedt, D. S., Grindem, H., Axe, M. J., Risberg, M. A., Engebretsen, L., . . S Snyder-Mackler, L. (2016). Does extended preoperative rehabilitation influence outcomes 2 years after $A C L$ reconstruction? A comparative effectiveness study between the MOON and Delaware-Oslo ACL cohorts. American Journal of Sports Medicine, 44(10), 2608-2614. https://doi.org/10.1177/0363546516652594

Feller, J., Webster, K., Taylor, N., Payne, R., \& Pizzari, T. (2004). Effect of physiotherapy attendance on outcome after anterior cruciate ligament reconstruction: A pilot study. British Journal of Sports Medicine, 38(1), 74-77. https://doi.org/10.1136/bjsm.2003.005181

Feucht, M. J., Cotic, M., Saier, T., Minzlaff, P., Plath, J. E., Imhoff, A. B., \& Hinterwimmer, S. (2016). Patient expectations of primary and revision anterior cruciate ligament reconstruction. Knee Surgery, Sports Traumatology, Arthroscopy, 24(1), 201-207. https://doi.org/10.1007/ s00167-014-3364-z

Filbay, S., \& Grindem, H. (2019). Evidence-based recommendations for the management of anterior cruciate ligament $(A C L)$ rupture. Best Practice \& Research Clinical Rheumatology, 33(1), 33-47. https://doi.org/10.1016/j. berh.2019.01.018

Filbay, S., Roos, E. M., Frobell, R. B., Roemer, F., Ranstam, J., \& Lohmander, L. S. (2017). Delaying ACL reconstruction and treating with exercise therapy alone may alter prognostic factors for 5-year outcome: An exploratory analysis of the KANON trial. British Journal of Sports Medicine, 51(22), 1622-1629. https://doi.org/10.1136/bjsports-2016-097124
Fitzjohn, P. (2007). Physiotherapy services report released. Retrieved from http://www.scoop.co.nz/stories/PA0711/S00323/physiotherapy-servicesreport-released.htm

Flood, C. M. (2000). New Zealand's no-fault accident compensation scheme: Paradise or panacea? Health Law Review, 8(3), 1-9.

Gianotti, S. M., Marshall, S. W., Hume, P. A., \& Bunt, L. (2009). Incidence of anterior cruciate ligament injury and other knee ligament injuries: A national population-based study. Journal of Science and Medicine in Sport, 12(6), 622-627. https://doi.org/10.1016/j.jsams.2008.07.005

Grant, J. A., \& Mohtadi, N. G. (2010). Two- to 4-year follow-up to a comparison of home versus physical therapy-supervised rehabilitation programs after anterior cruciate ligament reconstruction. American Journal of Sports Medicine, 38(7), 1389-1394. https://doi. org/10.1177/0363546509359763

Greenberg, E. M., Greenberg, E. T., Albaugh, J., Storey, E., \& Ganley, T. J. (2018). Rehabilitation practice patterns following anterior cruciate ligament reconstruction: A survey of physical therapists. Journal of Orthopaedic and Sports Physical Therapy, 48(10), 801-811. https://doi. org/10.2519/jospt.2018.8264

Grindem, H., Arundale, A., \& Ardern, C. (2018). Alarming underutilisation of rehabilitation in athletes with anterior cruciate ligament reconstruction: Four ways to change the game. British Journal of Sports Medicine, 52(18), 1162-1163. https://doi.org/10.1136/bjsports-2017-098746

Grindem, H., Granan, L., Risberg, M., Engebretsen, L., Snyder-Mackler, L., \& Eitzen, I. (2015). How does a combined preoperative and postoperative rehabilitation programme influence the outcome of $A C L$ reconstruction 2 years after surgery? A comparison between patients in the Delaware-Oslo $\mathrm{ACL}$ Cohort and the Norwegian National Knee Ligament Registry. British Journal of Sports Medicein, 49(6), 385-389. https://doi.org/10.1136/ bjsports-2014-093891

Grindem, H., Risberg, M., \& Eitzen, I. (2015). Two factors that may underpin outstanding outcomes after $\mathrm{ACL}$ rehabilitation. British Journal of Sports Medicine, 49(22), 1425. https://doi.org/10.1136/bjsports-2015-095194

Grindem, H., Snyder-Mackler, L., Moksnes, H., Engebretsen, L., \& Risberg, M. (2016). Simple decision rules can reduce reinjury risk by $84 \%$ after $A C L$ reconstruction: The Delaware-Oslo $A C L$ cohort study. British Journal of Sports Medicine, 50(13), 804-808. https://doi.org/10.1136/ bjsports-2016-096031

Han, F., Banerjee, A., Shen, L., \& Krishna, L. (2015). Increased compliance with supervised rehabilitation improves functional outcome and return to sport after anterior cruciate ligament reconstruction in recreational athletes. Orthopaedic Journal of Sports Medicine, 3(12), 2325967115620770. https://doi.org/10.1177/2325967115620770

Heijne, A., Axelsson, K., Werner, S., \& Biguet, G. (2008). Rehabilitation and recovery after anterior cruciate ligament reconstruction: Patients experiences. Scandinavian Journal of Medicine \& Science in Sports, 18(3), 325-335. https://doi.org/10.1111/j.1600-0838.2007.00700.x

Heijne, A., \& Werner, S. (2007). Early versus late start of open kinetic chain quadriceps exercises after $A C L$ reconstruction with patellar tendon or hamstring grafts: A prospective randomized outcome study. Knee Surgery, Sports Traumatology, Arthroscopy, 15(4), 402-414. https://doi org/10.1007/s00167-006-0246-z

Hohmann, E., Tetsworth, K., \& Bryant, A. (2011). Physiotherapy-guided versus home-based, unsupervised rehabilitation in isolated anterior cruciate injuries following surgical reconstruction. Knee Surgery, Sports Traumatology, Arthroscopy, 19(7), 1158-1167. https://doi.org/10.1007/ s00167-010-1386-8

Janssen, K., Orchard, J., Driscoll, T., \& Van Mechelen, W. (2012). High incidence and costs for anterior cruciate ligament reconstructions performed in Australia from 2003-2004 to 2007-2008: Time for an anterior cruciate ligament register by Scandinavian model? Scandinavian Journal of Medicine \& Science in Sports, 22(4), 495-501. https://doi. org/10.1111/j.1600-0838.2010.01253.x

Khair, M. M., Ghomrawi, H., Wilson, S., \& Marx, R. G. (2018). Patient and surgeon expectations prior to anterior cruciate ligament reconstruction. HSS Journal, 14(3), 282-285. https://doi.org/10.1007/s11420-018-9623-7 
Khan, T., Alvand, A., Prieto-Alhambra, D., Culliford, D. J., Judge, A., Jackson, W. F., ... Price, A. J. (2018). ACL and meniscal injuries increase the risk of primary total knee replacement for osteoarthritis: A matched casecontrol study using the Clinical Practice Research Datalink (CPRD). British Journal of Sports Medicine, 53(15), 965-968. https://doi.org/10.1136/ bjsports-2017-097762

Lai, C. C., Ardern, C. L., Feller, J. A., \& Webster, K. E. (2017). Eighty-three per cent of elite athletes return to preinjury sport after anterior cruciate ligament reconstruction: A systematic review with meta-analysis of return to sport rates, graft rupture rates and performance outcomes. Br J Sports Med, 52(2), 128-138. https://doi.org/10.1136/bjsports-2016-096836

Larsen, J. B., Farup, J., Lind, M., \& Dalgas, U. (2015). Muscle strength and functional performance is markedly impaired at the recommended time point for sport return after anterior cruciate ligament reconstruction in recreational athletes. Human Movement Science, 39, 73-87. https://doi. org/10.1016/j.humov.2014.10.008

Lattermann, C., Conley, C. E.-W., Johnson, D. L., Reinke, E. K., Huston, L. J., Huebner, J. L., . . Jacobs, C. A. (2018). Select biomarkers on the day of anterior cruciate ligament reconstruction predict poor patientreported outcomes at 2-year follow-up: A pilot study. BioMed Research International, 2018, 9387809. https://doi.org/10.1155/2018/9387809

Lee, Y. S., Lee, O.-S., Lee, S. H., \& Hui, T. S. (2018). Effect of the timing of anterior cruciate ligament reconstruction on clinical and stability outcomes: A systematic review and meta-analysis. Arthroscopyy, 34(2), 592-602. https://doi.org/10.1016/j.arthro.2017.07.023

Lobb, R., Tumilty, S., \& Claydon, L. S. (2012). A review of systematic reviews on anterior cruciate ligament reconstruction rehabilitation. Physical Therapy in Sport, 13(4), 270-278. https://doi.org/10.1016/j. ptsp.2012.05.001

Logerstedt, D., Lynch, A., Axe, M. J., \& Snyder-Mackler, L. (2013). Preoperative quadriceps strength predicts IKDC2000 scores 6 months after anterior cruciate ligament reconstruction. Knee, 20(3), 208-212. https:// doi.org/10.1016/j.knee.2012.07.011

Majewski, M., Susanne, H., \& Klaus, S. (2006). Epidemiology of athletic knee injuries: a 10-year study. Knee, 13(3), 184-188. https://doi.org/10.1016/j. knee.2006.01.005

Makhni, E. C., Crump, E. K., Steinhaus, M. E., Verma, N. N., Ahmad, C. S., Cole, B. J., \& Bach Jr, B. R. (2016). Quality and variability of online available physical therapy protocols from academic orthopaedic surgery programs for anterior cruciate ligament reconstruction. Arthroscopy, 32(8), 1612-1621. https://doi.org/10.1016/j.arthro.2016.01.033

Ministry of Health. (2001). The primary health care strategy. Wellington: Ministry of Health Retrieved from https://www.health.govt.nz/system/files/ documents/publications/phcstrat_0.pdf

Ministry of Health. (2016). New Zealand health strategy: Roadmap of actions Retrieved from https://www.health.govt.nz/system/files/documents/ publications/new-zealand-health-strategy-roadmapofactions-2016-apr16. pdf

Moksnes, H., Snyder-Mackler, L., \& Risberg, M. A. (2008). Individuals with an anterior cruciate ligament-deficient knee classified as noncopers may be candidates for nonsurgical rehabilitation. Journal of Orthopaedic \& Sports Physical Therapy, 38(10), 586-595. https://doi.org/10.2519/ jospt.2008.2750

Moses, B., Orchard, J., \& Orchard, J. (2012). Systematic review: Annual incidence of $A C L$ injury and surgery in various populations. Research in Sports Medicine, 20(3-4), 157-179. https://doi.org/10.1080/15438627.2 012.680633

Myer, G. D., Martin Jr, L., Ford, K. R., Paterno, M. V., Schmitt, L. C., Heidt Jr, R. S., . . Hewett, T. E. (2012). No association of time from surgery with functional deficits in athletes after anterior cruciate ligament reconstruction: Evidence for objective return-to-sport criteria. American Journal of Sports Medicine, 40(10), 2256-2263. https://doi. org/10.1177/0363546512454656

Myer, G. D., Paterno, M. V., Ford, K. R., Quatman, C. E., \& Hewett, T. E. (2006). Rehabilitation after anterior cruciate ligament reconstruction: Criteria-based progression through the return-to-sport phase. Journal of Orthopaedic and Sports Physical Therapy, 36(6), 385-402. https://doi. org/10.2519/jospt.2006.2222
Noyes, F., Matthews, D., Mooar, P., \& Grood, E. (1983). The symptomatic anterior cruciate-deficient knee. Part II: The results of rehabilitation, activity modification, and counseling on functional disability. Journal of Bone and Joint Surgery (American), 65(2), 163-174. https://doi. org/10.2106/00004623-198365020-00004

New Zealand ACL Registry. (2018). 2018 NZ ACL registry annual report. Retrieved from https://www.aclregistry.nz/reports/

Øiestad, B. E., Holm, I., \& Risberg, M. A. (2018). Return to pivoting sport after $A C L$ reconstruction: Association with osteoarthritis and knee function at the 15-year follow-up. British Journal of Sports Medicine, 52(18), 11991204. https://doi.org/10.1136/bjsports-2017-097718

Physiotherapy New Zealand. (2018). Physiotherapy New Zealand remuneration survey. Retrieved from https://pnz.org.nz/ Folder?Action=View\%20File\&Folder_id=1\&File=2018\%20PNZ\%20 Remuneration\%20Survey\%20report\%20(FINAL).pdf

Pizzari, T., McBurney, H., Taylor, N. F., \& Feller, J. A. (2002). Adherence to anterior cruciate ligament rehabilitation: A qualitative analysis. Journal of Sport Rehabilitation, 11(2), 90-102

Pizzari, T., Taylor, N. F., McBurney, H., \& Feller, J. A. (2005). Adherence to rehabilitation after anterior cruciate ligament reconstructive surgery: Implications for outcome. Journal of Sport Rehabilitation, 14(3), 201-214.

Risberg, M. A., Grindem, H., \& Oiestad, B. E. (2016). We need to implement current evidence in early rehabilitation programs to improve long-term outcome after anterior cruciate ligament injury. Journal of Orthopaedic and Sports Physical Therapy, 46(9), 710-713. https://doi.org/10.2519/ jospt.2016.0608

Risberg, M. A., \& Holm, I. (2009). The long-term effect of 2 postoperative rehabilitation programs after anterior cruciate ligament reconstruction: A randomized controlled clinical trial with 2 years of follow-up. American Journal of Sports Medicine, 37(10), 1958-1966. https://doi. org/10.1177/0363546509335196

Risberg, M. A., Lewek, M., \& Snyder-Mackler, L. (2004). A systematic review of evidence for anterior cruciate ligament rehabilitation: How much and what type? Physical Therapy in Sport, 5(3), 125-145. https://doi. org/10.1016/j.ptsp.2004.02.003

Rosso, F., Bonasia, D. E., Cottino, U., Cambursano, S., Dettoni, F., \& Rossi, R (2018). Factors affecting subjective and objective outcomes and return to play in anterior cruciate ligament reconstruction: a retrospective cohort study. Joints, 6(1), 23-32. https://doi.org/10.1055/s-0038-1636931

Sanders, T. L., Maradit Kremers, H., Bryan, A. J., Kremers, W. K., Levy, B. A. Dahm, D. L., ... Krych, A. J. (2016). Incidence of and factors associated with the decision to undergo anterior cruciate ligament reconstruction 1 to 10 years after injury. American Journal of Sports Medicine, 44(6), 1558-1564. https://doi.org/10.1177/0363546516630751

Sanders, T. L., Maradit Kremers, H., Bryan, A. J., Larson, D. R., Dahm, D. L., Levy, B. A., ... Krych, A. J. (2016). Incidence of anterior cruciate ligament tears and reconstruction: a 21-year population-based study American Journal of Sports Medicine, 44(6), 1502-1507. https://doi. org/10.1177/0363546516629944

Scheppers, E., Van Dongen, E., Dekker, J., Geertzen, J., \& Dekker, J. (2006). Potential barriers to the use of health services among ethnic minorities: A review. Family Practice, 23(3), 325-348. https://doi.org/10.1093/fampra/ cmi113

Scott, S. M., Perry, M. A., \& Sole, G. (2018). "Not always a straight path": patients' perspectives following anterior cruciate ligament rupture and reconstruction. Disability and Rehabilitation, 40(19), 2311-2317. https:// doi.org/10.1080/09638288.2017.1335803

Smith, T. O., Postle, K., Penny, F., McNamara, I., \& Mann, C. J. (2014). Is reconstruction the best management strategy for anterior cruciate ligament rupture? A systematic review and meta-analysis comparing anterior cruciate ligament reconstruction versus non-operative treatment. Knee, 21(2), 462-470. https://doi.org/10.1016/j.knee.2013.10.009

Suter, L. G., Smith, S. R., Katz, J. N., Englund, M., Hunter, D. J., Frobell, R., \& Losina, E. (2017). Projecting lifetime risk of symptomatic knee osteoarthritis and total knee replacement in individuals sustaining a complete anterior cruciate ligament tear in early adulthood. Arthritis Care \& Research, 69(2), 201-208. https://doi.org/10.1002/acr.22940 
Thoma, L. M., Grindem, H., Logerstedt, D., Axe, M., Engebretsen, L., Risberg, M. A., \& Snyder-Mackler, L. (2019). Coper classification early after anterior cruciate ligament rupture changes with progressive neuromuscular and strength training and is associated with 2-year success: The Delaware-Oslo ACL Cohort Study. American Journal of Sports Medicine, 47(4), 807-814. https://doi.org/10.1177/0363546519825500

Thorstensson, C. A., Lohmander, L. S., Frobell, R. B., Roos, E. M., \& Gooberman-Hill, R. (2009). Choosing surgery: patients' preferences within a trial of treatments for anterior cruciate ligament injury. A qualitative study. BMC Musculoskeletal Disorders, 10, 100. https://doi. org/10.1186/1471-2474-10-100

van Melick, N., van Cingel, R. E., Brooijmans, F., Neeter, C., van Tienen, T., Hullegie, W., \& Nijhuis-van der Sanden, M. W. (2016). Evidencebased clinical practice update: practice guidelines for anterior cruciate ligament rehabilitation based on a systematic review and multidisciplinary consensus. British Journal of Sports Medicine, 50(24), 1506-1515. https:// doi.org/10.1136/bjsports-2015-095898

van Yperen, D. T., Reijman, M., van Es, E. M., Bierma-Zeinstra, S. M., \& Meuffels, D. E. (2018). Twenty-year follow-up study comparing operative versus nonoperative treatment of anterior cruciate ligament ruptures in high-level athletes. American Journal of Sports Medicine, 46(5), 11291136. https://doi.org/10.1177/0363546517751683

Vermeire, E., Hearnshaw, H., Van Royen, P., \& Denekens, J. (2001). Patient adherence to treatment: three decades of research. A comprehensive review. Journal of Clinical Pharmacy and Therapeutics, 26(5), 331-342. https://doi.org/10.1046/j.1365-2710.2001.00363.x

von Aesch, A. V., Perry, M., \& Sole, G. (2016). Physiotherapists' experiences of the management of anterior cruciate ligament injuries. Physical Therapy in Sport, 19, 14-22. https://doi.org/10.1016/j.ptsp.2015.08.004

Webster, K. E., \& Feller, J. A. (2016). Exploring the high reinjury rate in younger patients undergoing anterior cruciate ligament reconstruction. American Journal of Sports Medicine, 44(11), 2827-2832. https://doi. org/10.1177/0363546516651845
Webster, K. E., \& Feller, J. A. (2018). Return to level I sports after anterior cruciate ligament reconstruction: Evaluation of age, sex, and readiness to return criteria. Orthopaedic Journal of Sports Medicine, 6(8), 325967118763763. https://doi.org/10.1177/2325967118788045

Webster, K. E., \& Feller, J. A. (2019). Expectations for return to preinjury sport before and after anterior cruciate ligament reconstruction. American Journal of Sports Medicine, 47(3), 578-583. https://doi. org/10.1177/0363546518819454

Wiggins, A. J., Grandhi, R. K., Schneider, D. K., Stanfield, D., Webster, K. E., \& Myer, G. D. (2016). Risk of secondary injury in younger athletes after anterior cruciate ligament reconstruction: A systematic review and metaanalysis. American Journal of Sports Medicine, 44(7), 1861-1876. https:// doi.org/10.1177/0363546515621554

Wittenberg, R. H., Oxfort, H. U., \& Plafki, C. (1998). A comparison of conservative and delayed surgical treatment of anterior cruciate ligament ruptures. International Orthopaedics, 22(3), 145-148. https://doi. org/10.1007/s002640050228

Wright, R. W., Magnussen, R. A., Dunn, W. R., \& Spindler, K. P. (2011). Ipsilateral graft and contralateral $A C L$ rupture at five years or more following $A C L$ reconstruction: A systematic review. Journal of Bone and Joint Surgery (American), 93(12), 1159-1165. https://doi.org/10.2106/ JBJS.J.00898

Zadro, J. R., \& Pappas, E. (2018). Time for a different approach to anterior cruciate ligament injuries: Educate and create realistic expectations. Sports Medicine, 49(3), 357-363. https://doi.org/10.1007/s40279-018-0995-0

Zbrojkiewicz, D., Vertullo, C., \& Grayson, J. E. (2018). Increasing rates of anterior cruciate ligament reconstruction in young Australians, 2000-2015. Medical Journal of Australia, 208(8), 354-358. https://doi. org/10.5694/mja17.00974 